\title{
Finite Element Analysis about Compressive Strength and Heat Transfer Coefficient of New Composite Insulation Block
}

\author{
Zhixin Yue ${ }^{1}$, Baishou $\mathrm{Li}^{1}$ \\ ${ }^{1}$ Department of structural engineering, Yanbian University, Yanji, 133002, China
}

\begin{abstract}
Keywords: composite insulation block, compressive strength, heat transfer coefficient, recycled concrete, finite element analysis.
\end{abstract}

\begin{abstract}
In north China, exterior insulation technology is adopted, brings a series of problems such as the lives of outer insulation material and building are different. A new composite insulation block has been put forward to solve these problems. The compressive strength and heat transfer coefficient of normal concrete composite insulation block (NC-190) was analyzed by ANSYS. Its simulation error is less than $10 \%$. It can reflect the real working state. With this method, we forecast the compressive strength and heat transfer coefficient of recycled concrete composite insulation block (RC-190) with 100\% recycled aggregate replacement ration. Its compressive strength 5.54MPa meets the non-load-bearing blocks' strength requirements according to "Technical Specification for Concrete Small-Sized Hollow Block Masonry Buildings". Its heat transfer coefficient $0.585 \mathrm{~W} /\left(\mathrm{m}^{2} \cdot \mathrm{k}\right)$ meets the thermal insulation requirements of external wall in Yanji City (shape coefficient less than 0.3) according to “The Civil Building Energy-Saving Design Standard”.
\end{abstract}

\section{Introduction}

With the rapid development of Chinese construction industry, construction waste emissions are also increasing year by year, which affects the further development of the national economy seriously. At the same time, Chinese building energy-saving standard has been increased to 65\% [1], energysaving requirements become higher and higher. Most blocks just extend the heat transfer path, can't solve the thermal bridge problem fundamentally [2].In north China, people adopt exterior insulation technology, which brings a series of problems such as the lives of the outer EPS insulation material and building are not the same.

To solve the problems mentioned above, Wang studied the heat transfer coefficient (HTC) and compressive strength (CS) of NC-190 [1]. On this basis, this paper researches CS and HTC of NC190 by ANSYS, analyzes the error of simulation values to test values, forecasts CS and HTC of RC-190, studying the feasibility of using finite element analysis method to guide later tests and engineering application.

\section{Test of compressive strength}

We used P.O 42.5 ordinary Portland cement produced by Jilin Yatai Group. The fineness modulus of fine sand is 2.8 and its size is $0.25 \sim 3 \mathrm{~mm}$. For every concrete layer is only $30 \mathrm{~mm}$ thick, we used crushed stone with size $5 \sim 10 \mathrm{~mm}$ [3].

Figure 1 shows the $3 d$ model diagram of the new composite insulation block. It is composed by three layers of concrete and two layers of thermal insulation material. The two inner concrete layers are main force structure, connected by concrete bar and plastic bar. The outer concrete layer is decorative layer, connected by plastic bar only with the main body. Figure 2 shows its three view drawings. Table 1 shows the 28d compressive strength. 

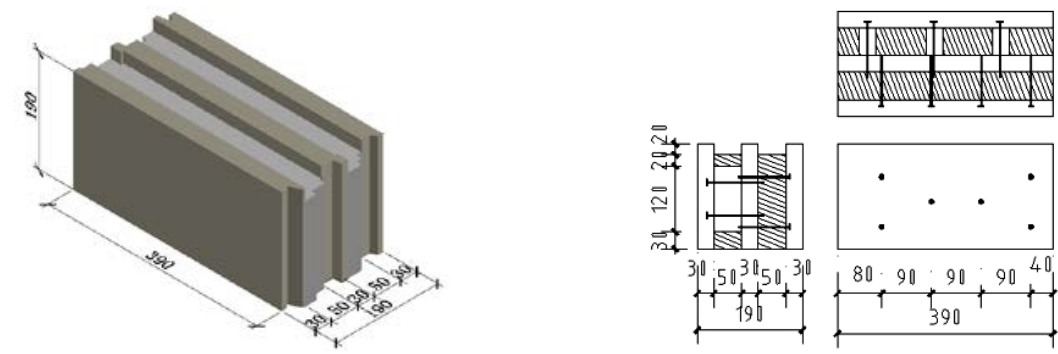

Fig. 1 The 3d model diagram of block Fig. 2 The three view drawings of block

Table 1: The compressive strength test of concrete blocks

\begin{tabular}{cccc}
\hline No. & $\begin{array}{c}\text { Cubic compressive } \\
\text { strength (MPa) }\end{array}$ & $\begin{array}{c}\text { Block compressive } \\
\text { strength (MPa) }\end{array}$ & $\begin{array}{c}\text { Block average compressive } \\
\text { strength (MPa) }\end{array}$ \\
\hline 1 & & 6.59 & \\
2 & 24.5 & 6.64 & 6.63 \\
3 & & 6.67 & \\
\hline
\end{tabular}

\section{Thermal performance}

50 NC-190 blocks are commissioned for testing in construction engineering quality test center of Jilin Province. Based on GB/T 13475-2008[4], HTC of blocks is $0.418 \mathrm{~W} /\left(\mathrm{m}^{2} \cdot \mathrm{k}\right)<0.6 \mathrm{~W} /\left(\mathrm{m}^{2} \cdot \mathrm{k}\right)$, meeting the requirements of thermal insulation for building external wall in Yanji City (shape coefficient $\leq 0.3$ ) according to "The Civil Building Energy-Saving Design Standard”[5].

“Thermal Design Code for Civil Buildings” (GB50176-93) [6] gives the following thermal resistance calculation equation:

i) A single material layer thermal resistance is calculated according to the following equation:

$$
R=\frac{\delta}{\lambda}
$$

$\mathrm{R}$-The thermal resistance of material layer $\left(\mathrm{m}^{2} \cdot \mathrm{K} / \mathrm{W}\right)$;

$\delta$-The thickness of material layer (m);

$\lambda$-The thermal conductivity of materials $[\mathrm{W} /(\mathrm{m} \cdot \mathrm{K})]$, it should be used according to the provisions of the specification appendix and table note.

ii) Multilayer building envelope thermal resistance is calculated according to the following equation:

$$
R=R_{1}+R_{2}+\cdots \cdots+R_{n}
$$

$\mathrm{R} 1+\mathrm{R} 2+\cdots \cdots+\mathrm{R}_{\mathrm{n}}$-The thermal resistance of material layers $\left(\mathrm{m}^{2} \cdot \mathrm{K} / \mathrm{W}\right)$.

iii) For heterogeneous retaining structure composed of two or more materials, the average thermal resistance is calculated according to the following equation (Figure 3 is the thermal calculation chart):

$$
\bar{R}=\left[\frac{F_{0}}{\frac{F_{1}}{R_{0.1}}+\frac{F_{2}}{R_{0.2}}+\cdots+\frac{F_{n}}{R_{0 . n}}}-\left(R_{i}+R_{e}\right)\right] \varphi
$$

$\bar{R}$-Average thermal resistance $\left(\mathrm{m}^{2} \cdot \mathrm{K} / \mathrm{W}\right)$;

$\mathrm{F}_{0}$-The total heat transfer area perpendicular to the direction of heat flow $\left(\mathrm{m}^{2}\right)$;

$\mathrm{F}_{1}, \mathrm{~F}_{2} \cdots \mathrm{F}_{\mathrm{n}}$-The heat transfer areas parallel to the direction of heat flow $\left(\mathrm{m}^{2}\right)$;

$\mathrm{R}_{0.1}, \mathrm{R}_{0.2} \cdots \mathrm{R}_{0 . \mathrm{n}}$-The thermal resistances of each heat transfer area $\left(\mathrm{m}^{2} \cdot \mathrm{K} / \mathrm{W}\right)$;

$\mathrm{R}_{\mathrm{i}}$-The inner surface heat transfer resistance, values $0.11\left(\mathrm{~m}^{2} \cdot \mathrm{K} / \mathrm{W}\right)$;

$\mathrm{R}_{\mathrm{e}}$-The Outer surface heat transfer resistance, values $0.4\left(\mathrm{~m}^{2} \cdot \mathrm{K} / \mathrm{W}\right)$;

$\varphi$-Correction factor, it should be used according to the provisions of the specification appendix. 


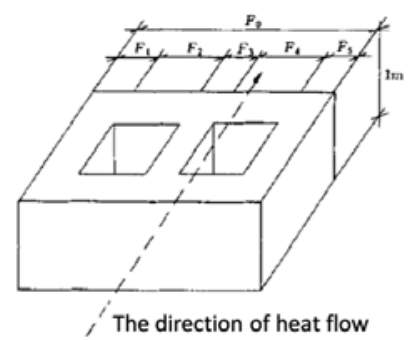

Fig. 3: The thermal calculation chart

iv) The heat transfer resistance of building envelope is calculated according to the following equation:

$$
R_{0}=R_{i}+R+R_{e}
$$

$\mathrm{R}_{0}$-The heat transfer resistance of building envelope $\left(\mathrm{m}^{2} \cdot \mathrm{K} / \mathrm{W}\right)$;

$\mathrm{R}$-Thermal resistance of building envelope $\left(\mathrm{m}^{2} \cdot \mathrm{K} / \mathrm{W}\right)$.

The specification states the thermal conductivity of normal concrete (NC) is $1.74 \mathrm{~W} /\left(\mathrm{m}^{2} \cdot \mathrm{K}\right)$, polystyrene insulation board is $0.042 \mathrm{~W} /\left(\mathrm{m}^{2} \cdot \mathrm{K}\right)$. Because the insulation board has compression and moisture absorption effect as a laminate in the concrete, its thermal conductivity should be multiplied by a correction factor 1.2 , its value is $0.05 \mathrm{~W} /\left(\mathrm{m}^{2} \cdot \mathrm{k}\right)$. Increasing $15 \mathrm{~mm}$ thick mortar layer inside the block, its thermal conductivity is $0.93 \mathrm{~W} /\left(\mathrm{m}^{2} \cdot \mathrm{k}\right)$. The thermal conductivity of recycled concrete (RC) is $1.48 \mathrm{~W} /\left(\mathrm{m}^{2} \cdot \mathrm{k}\right), 85 \%$ of the normal concrete [7]. For easy calculation, the block is decomposed into two sections (shown in Figure 4). The end section (no concrete bar) accounts for $36.8 \%$ and the middle section (with concrete bar) accounts for $63.2 \%$. Table 2 shows calculation results.

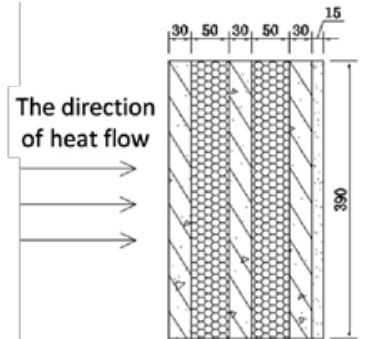

a) The end of block K1

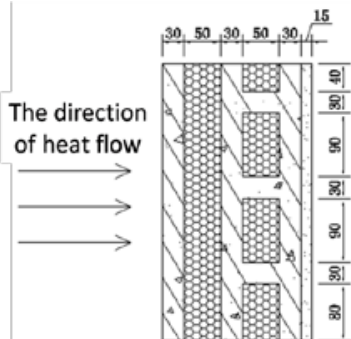

b) The middle of block

Fig. 4: The calculation diagram of resolution block

Table 2: The heat transfer coefficient of blocks

\begin{tabular}{cccc}
\hline Type & $\begin{array}{c}\text { End section } \\
\left(\mathrm{m}^{2} \cdot \mathrm{K} / \mathrm{W}\right)\end{array}$ & $\begin{array}{c}\text { Middle section } \\
\left(\mathrm{m}^{2} \cdot \mathrm{K} / \mathrm{W}\right)\end{array}$ & $\begin{array}{c}\text { Total } \\
{\left[\mathrm{W} /\left(\mathrm{m}^{2} \cdot \mathrm{k}\right)\right]}\end{array}$ \\
\hline $\mathrm{NC}-190$ & 2.218 & 1.608 & 0.559 \\
$\mathrm{RC}-190$ & 2.227 & 1.619 & 0.556 \\
\hline
\end{tabular}

\section{Finite element simulation analysis}

Compressive strength simulation. Insulation boards don't participate in force basically, so neglecting insulation boards when modeling. Concrete is simulated by SOLID65 element. NC elastic modulus is according to the initial slope value of stress-strain curve. Poisson's ratio is 0.2 , uniaxial tensile strength is $1.54 \mathrm{MPa}$, transfer coefficient for opened crack is 0.35 , transfer coefficient for closed crack is 1.0, close crush switch [8]. NC constitutive relation is according to the Sargin equation (5). The strength grade of RC is the same as NC. And its rising period of constitutive relation curve $\left(\varepsilon \leq \varepsilon_{0}\right)$ is according to the Sargin equation (5), the down period $\left(\varepsilon_{0}<\varepsilon \leq \varepsilon_{\mathrm{cu}}\right)$ is according to the literature [9], refers to equation (6). Other physical parameters are the same as NC.

$$
\sigma=k_{3} f_{c} \frac{A\left(\varepsilon / \varepsilon_{0}\right)+(D-1)\left(\varepsilon / \varepsilon_{0}\right)^{2}}{1+(A-2)\left(\varepsilon / \varepsilon_{0}\right)+D\left(\varepsilon / \varepsilon_{0}\right)^{2}}
$$


In equation, $\mathrm{k}_{3}=1, \mathrm{f}_{\mathrm{c}}=13.4, \mathrm{~A}=1.7388, \mathrm{D}=0.5, \varepsilon_{0}=0.002$

$$
\sigma=f_{c} \frac{\varepsilon / \varepsilon_{0}}{b\left(\varepsilon / \varepsilon_{0}-1\right)^{2}+\varepsilon / \varepsilon_{0}}
$$

The relation between $\mathrm{b}$ and recycled aggregate replacement ration $\mathrm{r}$ refers to equation (7):

$$
b=0.8(7.6483 r+1.142)
$$

Plastic bars are simulated by LINK8 element, its elastic modulus value is 28.3GPa, Poisson's ratio is 0.4 , yield stress is $55 \mathrm{MPa}$, hardening slope is 5000 .

Figure 5 and Figure 6 show the 3d model block and meshing situation. Figure 7 shows the von Mises stress of blocks.

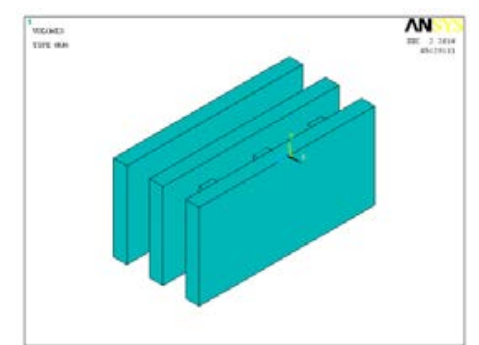

Fig. 5: The 3d model of block

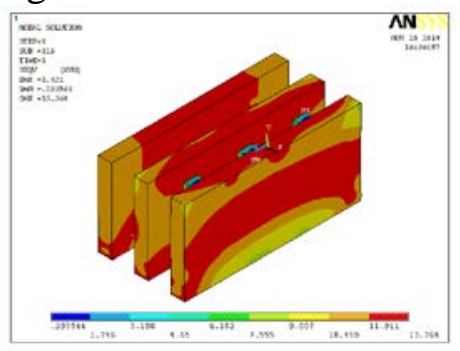

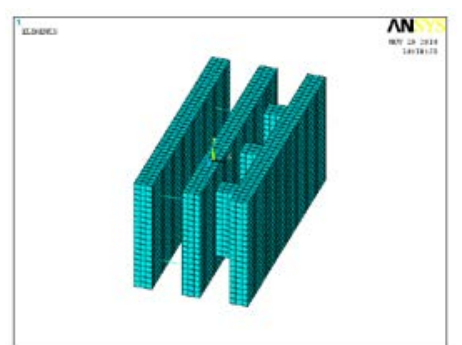

Fig. 6: The meshing situation

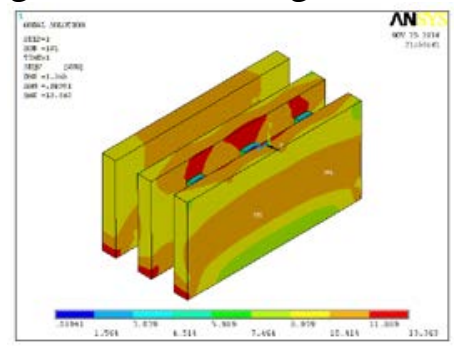

a) NC-190 b) RC-190

Fig. 7: The von Mises stress nephograms of two kinds of blocks

Figure 7 shows that the node stress distribution of the two types of concrete blocks are similar, because of the constitutive relation difference between NC and RC, the recycled aggregates have internal defects, leading to CS value of RC-190 block low. The result is consistent with actual status. This increase of three concrete bars improves the integrity of block, makes stress distribution of the main stress part more homogeneous, increasing CS of block, Table 3 shows the test value and ANSYS simulation value.

Table 3: The compressive strength of blocks

\begin{tabular}{cccc}
\hline Type & $\begin{array}{c}\text { Test values } \\
(\mathrm{MPa})\end{array}$ & $\begin{array}{c}\text { Simulation values } \\
(\mathrm{MPa})\end{array}$ & $\begin{array}{c}\text { Erro } \\
\mathrm{r}\end{array}$ \\
\hline $\begin{array}{c}\text { NC- } \\
190\end{array}$ & 6.63 & 6.17 & $\begin{array}{c}6.9 \\
\%\end{array}$ \\
$\begin{array}{c}\text { RC- } \\
190\end{array}$ & - & 5.54 & - \\
\hline
\end{tabular}

Table 3 shows the simulation value $6.17 \mathrm{MPa}$ is smaller than test value 6.63MPa, which is more secure, ANSYS simulation error is within 10\%. The predicted CS of RC-190 is 5.54MPa, meeting the non-load-bearing blocks' strength requirements according to "Technical Specification for Concrete Small-Sized Hollow Block Masonry Buildings” [10].

Thermal performance simulation.This paper simulates NC-190 and RC-190 separately and makes the following assumptions: It simplifies three dimensional component to two dimensional plane to solve; for boundary conditions, it supposes that the block and adjacent blocks are without heat exchange; block is in a steady temperature field, illustrated as the steady state heat conduction problem; concrete of blocks is in a good contact with the insulation board, the temperature in the contact surface is the same.

PLANE55 element is used for steady state thermal analysis, the outside temperature of the block is $263 \mathrm{k}$, the inside temperature is $308 \mathrm{k}$, air convection coefficient takes 2.5 , other thermal 
parameters are the same as the former, without regard to the influence of plastic bars to thermal performance.
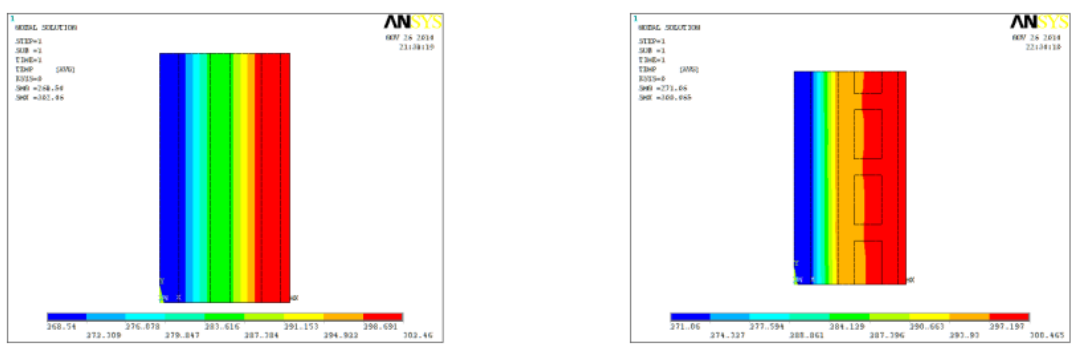

a) The endb) The middle

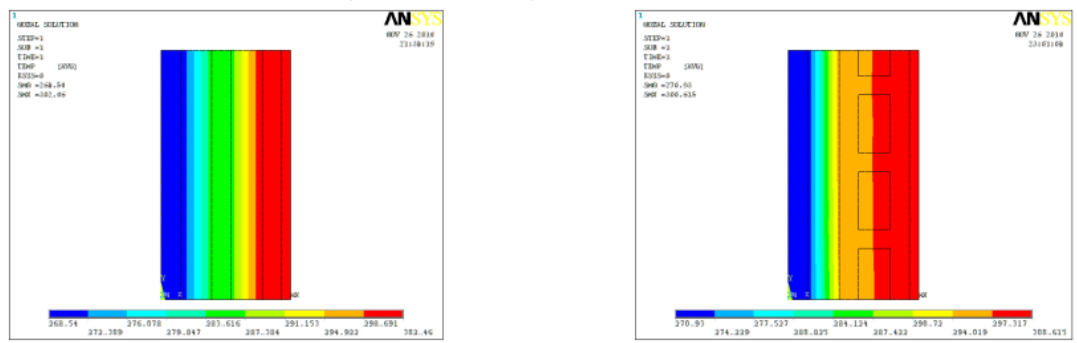

c) The endd) The middle

Fig. 8: The temperature field of normal (a-b) and recycled (c-d) concrete block
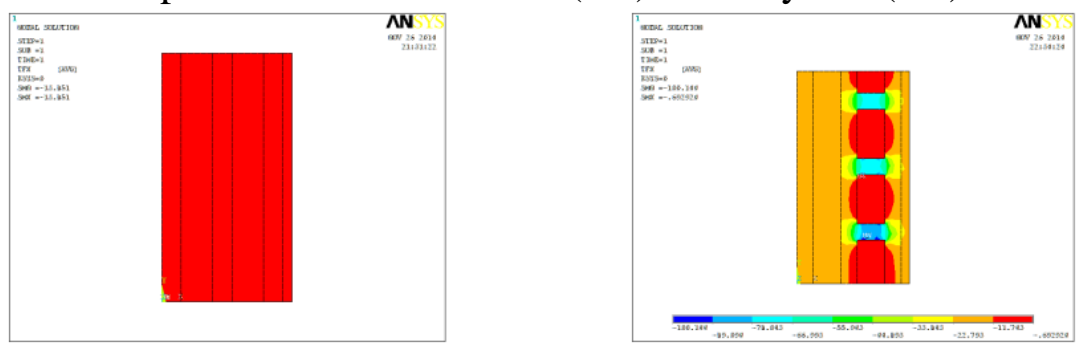

a) The endb) The middle
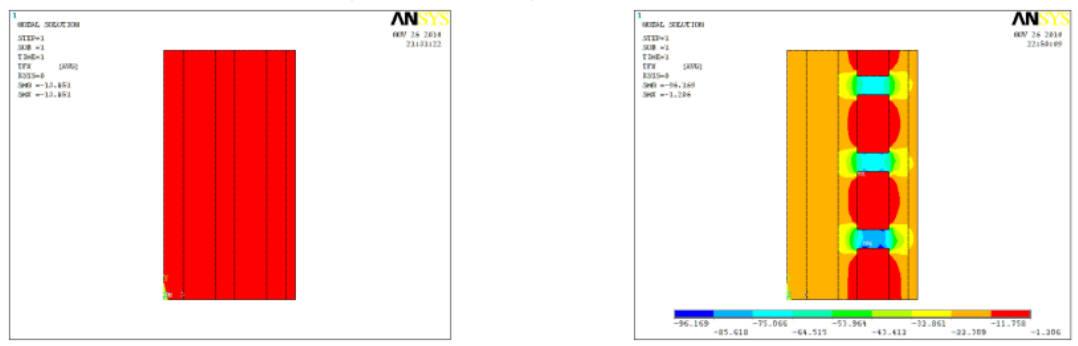

c) The endd) The middle

Fig. 9: The thermal flux of normal (a-b) and recycled (c-d) concrete block

Figure 8 shows that two kinds of concrete temperature field distributions are the same and the outer insulation board plays a better thermal insulation performance, blocking multiple temperature gradients. Concrete bars make the heat preservation effect of inner thermal insulation layer reduced. In Figure 9, the thermal flux distributions are also the same. The uniform distribution of materials makes thermal flux consistent in the end section. In the middle section, the thermal conductivity of concrete is much larger than Insulation board, so most of heat flows through the concrete bars.

Combined with ANSYS analysis results, we used the energy equilibrium equation of steady state thermal analysis (8) to calculate HTC of blocks shown in Table 4 [11].

$$
[K]\{T\}=\{Q\}
$$

In equation: [K]-Transmission matrix; $\{\mathrm{T}\}$-Temperature gradient vector; $\{\mathrm{Q}\}$-Heat flux vector. Table 4: The heat transfer coefficient of blocks

\begin{tabular}{cccc}
\hline Type & $\begin{array}{c}\text { Test values } \\
{\left[\mathrm{W} /\left(\mathrm{m}^{2} \cdot \mathrm{k}\right)\right]}\end{array}$ & $\begin{array}{c}\text { Calculation values } \\
{\left[\mathrm{W} /\left(\mathrm{m}^{2} \cdot \mathrm{k}\right)\right]}\end{array}$ & $\begin{array}{c}\text { Simulation values } \\
{\left[\mathrm{W} /\left(\mathrm{m}^{2} \cdot \mathrm{k}\right)\right]}\end{array}$ \\
\hline $\mathrm{NC}-190$ & 0.418 & 0.559 & 0.593 \\
$\mathrm{RC}-190$ & - & 0.556 & 0.585 \\
\hline
\end{tabular}


Table 4 shows that HTC calculation value and simulation value of NC-190 are both smaller than its test value, it can reflect block thermal performance accurately. HTC of RC-190 $0.585 \mathrm{~W} /\left(\mathrm{m}^{2} \cdot \mathrm{k}\right)$ is smaller than $\mathrm{NC}-1900.593 \mathrm{~W} /\left(\mathrm{m}^{2} \cdot \mathrm{k}\right)$ because of RC's lower thermal conductivity, its heat preservation effect has been increased for $1.3 \%$. Recycled aggregate has internal micro cracks, which make the porosity of recycled concrete much larger, reduce the thermal conductivity, improve the heat transfer resistance, obtaining better heat preservation effect.

\section{Conclusions}

Using ANSYS to make nonlinear analysis on CS of NC-190, its simulation value is smaller than test value, error within $10 \%$. It can reflect block's stressful situations accurately. Making theoretical analysis and finite element numerical analysis on the thermal performance of NC-190, its HTC calculation value and simulation value are both smaller than its test value, meeting the requirements of exterior wall thermal insulation in northeast China.

Using ANSYS to predict CS and HTC of RC-190 block, its stressful situation is similar to NC190 and its CS 5.54MPa is a little lower than NC-190's 6.17MPa, meeting the requirements of strength grade for non-bearing block. The distribution about temperature field and thermal flux of RC-190 and NC-190 is similar. HTC of RC-190 is only $0.585 \mathrm{~W} /\left(\mathrm{m}^{2} \cdot \mathrm{k}\right)$, its insulation effect has been increased for $1.3 \%$.

The simulation values of CS and HTC is similar to test values. The way of using ANSYS to predict CS and HTC of blocks can be for reference and its CS and HTC can satisfy the requirements of corresponding specifications. It has certain research value and practical significance to use recycled aggregates to produce new composite insulation blocks.

\section{Acknowledgements}

This work was financially supported by the 12th Five-Year "Double tenth" Project of Jilin provincial education office.

\section{References}

[1] Wang Li-Sha, Experimental Study on The Energy-Saving Sandwiched Self-Thermal Insulation Blocks. Yanji: Yanbian University Press, 2014.

[2] Jin Li-Hu, Compound insulation block block design and construction technology research. Wall Materials Innovation \& Energy Saving in Buildings, 2, pp.41-46, 2009.

[3] Wang Li-Sha, Li Bai-Shou, Quan Yun-Long \& Li Zhen-Shu, Experimental study on the energysaving sandwiched self-thermal insulation block masonry. China Concrete and Cement Products, 10, pp.67-71, 2014.

[4] GB/T 13475-2008, Thermal Insulation-Determination of Steady-State Thermal Transmission Properties-Calibrated and Guard Hot Box.

[5] JGJ 26-95, The Civil Building Energy-Saving Design Standard.

[6] GB 50176-93, Thermal Design Code for Civil Buildings.

[7] Xiao Jian-Zhuang, Song Zhi-Wen \& Zhang Feng, An experimental study on thermal conductivity of concrete. Journal of Building Materials, 1, pp.17-21, 2010.

[8] He Ben-Guo, ANSYS Civil Engineering Application Examples. Beijing: China Water Power Press, 2011.

[9] Xiao Jian-Zhuang, Recycled concrete. Beijing: China Building Industry Press, 2008.

[10] JGJ/T 14-2011, Technical Specification for Concrete Small-Sized Hollow Block Masonry Buildings. 
[11] Liu Cheng, The application of ANSYS thermal analysis technology in the pass layout of composite insulation blocks. Building Block and Block Building, 5, pp.14-22, 2012. 